\title{
Polymer optimization for the development of low-cost moisture sensor based on nanoporous alumina thin film
}

\author{
Manju PANDEY ${ }^{a}$, Prabhash MISHRA $^{a}$, Debdulal SAHA ${ }^{b}$, S. S. ISLAM ${ }^{a, *}$ \\ ${ }^{a}$ Nano-Sensor Research Laboratory, F/O Engineering and Technology, Jamia Millia Islamia (Central University), \\ New Delhi, India \\ ${ }^{b}$ Sensors and Actuators Division, Central Glass \& Ceramic Research Institute, 196 Raja S. C. Mullick Road, \\ Kolkata 700032, India
}

Received: July 18, 2013; Revised: August 16, 2013; Accepted: August 26, 2013

CThe Author(s) 2013. This article is published with open access at Springerlink.com

\begin{abstract}
Sol-gel processed alumina $\left(\mathrm{Al}_{2} \mathrm{O}_{3}\right)$ thin film has been investigated for sensing moisture. The sensor was based on ordered nanoporous $\mathrm{Al}_{2} \mathrm{O}_{3}$ thin film, which consisted of gold electrodes on both sides of the film forming parallel plate capacitor. Alumina substrate was used for supporting thin film moisture sensor. Hydrophilicity was achieved by controlling the surface energy of the substrate and polymer (polyvinyl alcohol (PVA)) optimization was done for developing rigid thin film over it. A high change in capacitance was observed as the moisture level increased from $5 \mathrm{ppmV}$ to $500 \mathrm{ppmV}$. Scanning electron microscopy (SEM) results revealed that pores were distributed uniformly throughout the sample, which enhanced the adsorption of water molecule over the film. X-ray diffraction (XRD) study clearly confirmed the gamma $(\gamma)$ phase of alumina thin film. It was found that the sensitivity of our sensor was suitable for commercial application.
\end{abstract}

Keywords: sol-gel; dip-coating; polyvinyl alcohol (PVA); nanoporous; hydrophilicity; moisture sensor

\section{Introduction}

As the increasing demand for a successful packaging in food industry, a technique to detect trace level of moisture during micro packaging has become more important. As we know, failures are mainly due to contaminants such as ambient moisture present in atmosphere, so a highly sensitive and stable moisture sensor has gotten much attention [1]. There is an

\footnotetext{
* Corresponding author.

E-mail: safiul5996@gmail.com
}

increasing interest in polymers for sensing applications [2]. A typical problem of polymers is their poor durability against water. In fact, polymeric materials used in moisture sensors are generally hydrophilic and sometimes even soluble in water. This problem is solved by sol-gel technique. Sol-gel is a chemical solution process used to make ceramic and glass materials at low temperature in the form of thin films, fibers or powders, in which sol is a colloidal or molecular suspension of solid particles of ions in a solvent. Sol-gel technology has received much attention in recent years in the field of sensing application. The reason behind is it is a low-cost, 
easier-fabrication and precisely-composition-control process [3]. On the other hand, sol-gel is suitable for preparing porous material because when the solvent from the sol begins to evaporate and the particles or ions left behind begin to join together in a continuous network, it forms a lot of cavities [4]. The properties of sol-gel processed ceramic materials can be improved by the addition of different types of porosity-control additives. The frequently used porosity-control additives are some organic polymers especially polyvinyl alcohol (PVA) to the colloidal solution, because it leads to the achievement of a very good rigidity of the resulted thin film product [5]. Yoldas [6] followed the method for preparing alumina sol. Preliminary studies on electrical behavior of $\mathrm{Al}_{2} \mathrm{O}_{3}$ thin films in the presence of trace level moisture have been carried out $[7,8]$. Result shows that $\mathrm{Al}_{2} \mathrm{O}_{3}$ thin films could form a good porous layer with nano-sized pores for trace moisture sensors. In present research work, ceramic moisture sensors [7,9-11] established their good sensitivity in the range of $5-500 \mathrm{ppmV}$ after optimizing the amount of polymer (PVA).

\section{Experiment}

\section{1 Preparation of alumina sol solution}

Alumina sol was prepared by Yoldas process [4]. Hydrolysis was performed by introducing an organometallic compound, Al-sec-butoxide $\left(\mathrm{AlC}_{12} \mathrm{H}_{27} \mathrm{O}_{3}\right)$ into de-ionized water (Al-sec-butoxide: water $=1: 25)$. Then the solution was peptized by dropwise adding hydrochloric acid (acid/alkoxide molar ratio $=0.07$ ) till it became transparent solution under continuous stirring at $90^{\circ} \mathrm{C}$. The peptized solution was then refluxed for about 14-16 h. After refluxing, three different concentrations of PVA which acted as binder were added into $50 \mathrm{ml}$ of refluxed sol. As we know, ceramic colloidal particles have the tendency of agglomeration in aqueous media. In general, aqueous suspensions can be stabilized by controlling the repulsive forces proceeding from a charged electric double layer, surrounding the particle (electrostatic stabilization), or from non-charged or charged polymers, adsorbed on the surface (steric and electrosteric stabilization, respectively) [12]. The electrokinetic or zeta potential measurements are used to estimate the electrostatic effect, which is responsible for the repulsive forces between the particles and estimates the suspension stability. Studies on particle electrokinetic have been proved to be useful where colloid stability is involved [13]. So for the development of crack-free thin film over the gold coated substrate, the zeta potential ( $\zeta$ ) of the sol was controlled to be $+22 \mathrm{mV}$ by adding $\mathrm{HCl}$ for uniform dispersion of the sol particles as shown in Fig. 1. From the zeta potential data, lower $\mathrm{pH}$ values promise better dispersing efficiencies with respect to higher surface charges yielding more intensive repulsive forces. A pH range of 2.0-3.0 appears to be the most beneficial working range in dispersing process of boehmite $(\mathrm{AlO}(\mathrm{OH}))$, because at this range repulsive forces between colloidal particles are very high as compared to other $\mathrm{pH}$ range and simultaneously it increases the stability of the boehmite sol.

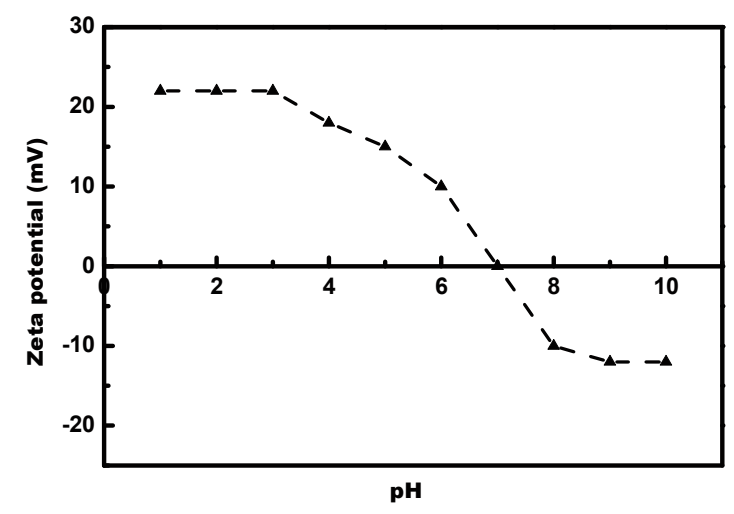

Fig. 1 Zeta potential curve for alumina sol.

\section{2 Development of capacitive humidity sensor}

The PVA mixed sol was coated on a gold-coated alumina substrate $(20 \mathrm{~mm} \times 20 \mathrm{~mm} \times 1 \mathrm{~mm})$ by dipping it in alumina sol at a speed of $10 \mathrm{~cm} / \mathrm{min}$ and then pulling out at a speed of $1 \mathrm{~cm} / \mathrm{min}$. The process was repeated eight times. This was followed by drying and then sintering the films at $450^{\circ} \mathrm{C}$ for $5 \mathrm{~h}$ with the heating and cooling rate of $100{ }^{\circ} \mathrm{C} / \mathrm{h}$. A stable $\gamma$ phase of alumina with high surface area [14] which is first priority for sensing mechanism was achieved after sintering and annealing the films. The second electrode using gold paste was developed by screen printing method on the alumina thin film coated substrate, and then finally fired at $950^{\circ} \mathrm{C}$ for curing the top gold electrode as illustrated in Fig. 2. The film between the gold electrodes was used as transducing layer for sensing the ambient trace moisture. The effective dielectric of the porous layer underwent a large change 
when water vapour diffused to the inner regions of the pore structure and was adsorbed on the porous layer. The capacitive sensor developed in this work consisted of a non-porous substrate coated with gold on which the thin films were deposited. It was covered by another porous electrode of gold. Contacts were taken from the two parallel gold electrodes. The water vapour was free to diffuse through the porous electrode to the porous alumina film and showed increase in capacitance. Figure 3 shows the photograph of the fabricated capacitive moisture sensors.

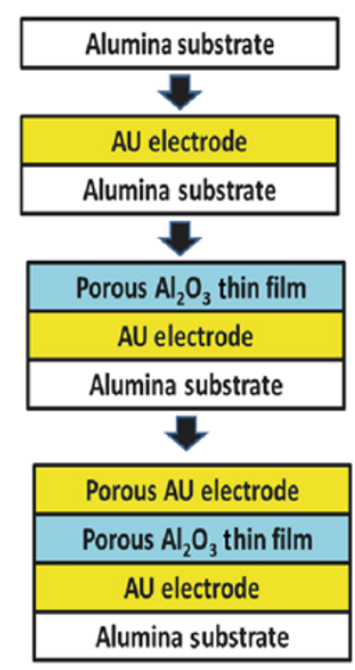

Fig. 2 Fabrication sequence of the moisture sensors based on alumina thin film.

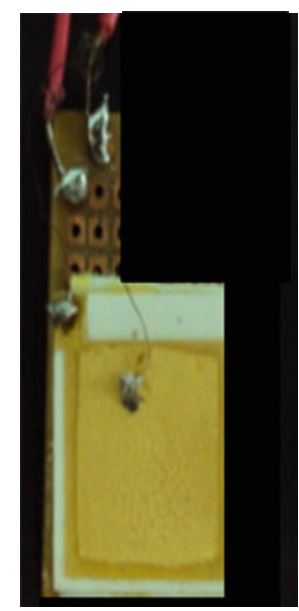

Fig. 3 Photograph of the moisture sensor.

\section{Results and discussion}

\section{1 Deposition of film by controlling the surface energy}

Sol-gel thin film coating on substrate depends on intrinsic properties of the coating and adhesion characteristics with the substrate material, which in turn, are controlled by the sol-gel processing parameters. Therefore, the interfacial adhesion properties of the film on substrate should be controlled by controlling the surface tension and contact angle between liquid and substrate using the sessile drop method. For developing rigid thin film over the substrate, it is very important that the difference between work of adhesion $\left(W_{\mathrm{a}}\right)$ and work of cohesion ( $\left.W_{\text {coh }}\right)$ should be positive with large value, only then does the film adhere properly with the substrate which is controlled by optimizing contact angle. Optimized PVA quantity plays an important role in rigidity. For optimization, three samples were prepared by using different concentrations of PVA into the alumina sol and then contact angle was measured over the substrate using drop of prepared sol as shown in Table 1.

The wettability of liquids on ceramics is often evaluated in terms of work of adhesion, $W_{\mathrm{a}}$, where $W_{\mathrm{a}}$ is usually determined from sessile drop experiment as shown in Fig. 4, in which surface tension $\sigma_{1 \mathrm{v}}$ and contact angle $\theta$ are measured by using Young-Dupre equation:

$$
W_{\mathrm{a}}=\sigma_{1 \mathrm{v}}(1+\cos \theta)
$$

The liquid surface tension is controlled so that the liquid angle of contact with the substrate should maintain

$$
W_{\mathrm{a}}>W_{\text {coh }}
$$

Table 1 Optimization of surface energy

\begin{tabular}{cccrcc}
\hline $\begin{array}{c}\text { Sample } \\
\text { No. }\end{array}$ & $\begin{array}{c}\text { PVA } \\
(\mathrm{g})\end{array}$ & $\begin{array}{c}\text { Contact } \\
\text { angle } \theta\end{array}$ & $\begin{array}{c}W_{\mathrm{a}} \\
(\mathrm{mN} / \mathrm{m})\end{array}$ & $\begin{array}{c}W_{\text {coh }} \\
(\mathrm{mN} / \mathrm{m})\end{array}$ & $\begin{array}{c}W_{\mathrm{a}}-W_{\text {coh }} \\
(\mathrm{mN} / \mathrm{m})\end{array}$ \\
\hline 1 & 0.5 & $74.40^{\circ}$ & 105.04 & 64.51 & 40.53 \\
2 & 1.0 & $65.23^{\circ}$ & 93.73 & 41.87 & 51.86 \\
3 & 1.5 & $37.64^{\circ}$ & 134.76 & 124.76 & 10.00 \\
\hline
\end{tabular}

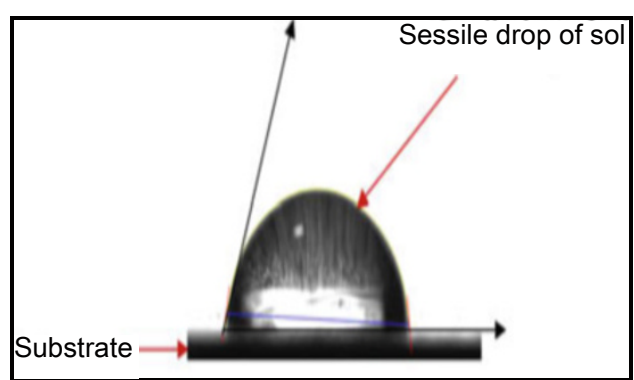

Fig. 4 Sessile-drop contact angle measurement. 


\section{2 Surface area and pore size analysis}

Porosity, surface area and pore size distribution are the basic quantities to specify a porous material. Brunauer, Emmet and Teller (BET) method was followed to measure surface area and Barrett-Joyner-Halenda (BJH) method for pore size distribution using surface area and pore size analyser (NOVA 2000e Model) as shown in Table 2. It yields well defined adsorption, desorption isotherms on most surfaces. The nitrogen adsorption isotherm gives the structural information about the network of micropores and mesopores. The formation of adsorption boundary curve is due to increase of pressure from zero to maximum value and desorption isotherm is for decrease of pressure from maximum to zero value. BET characterization was done after annealing the alumina films without gold electrode at $450{ }^{\circ} \mathrm{C}$ along with three different concentrations of PVA and then scratching them from the substrate.

Table 2 BET analysis for surface area, pore size and porosity present in $\gamma$ phase of alumina thin film

\begin{tabular}{ccccc}
\hline $\begin{array}{c}\text { Thin film } \\
\left(\mathrm{Al}_{2} \mathrm{O}_{3}\right)\end{array}$ & $\begin{array}{c}\text { Heat } \\
\text { treatment } \\
\left({ }^{\circ} \mathrm{C}, \mathrm{h}\right)\end{array}$ & $\begin{array}{c}\text { BET } \\
\text { surface } \\
\text { area }\left(\mathrm{m}^{2} / \mathrm{g}\right)\end{array}$ & $\begin{array}{c}\text { Pore } \\
\text { diameter } \\
(\mathrm{nm})\end{array}$ & $\begin{array}{c}\text { Porosity } \\
(\%)\end{array}$ \\
\hline With 0.5 g PVA & 450,5 & 110.2 & 8.02 & 60 \\
With 1.0 g PVA & 450,5 & 170.0 & 7.02 & 80 \\
With 1.5 g PVA & 450,5 & 200.0 & 6.89 & 83 \\
\hline
\end{tabular}

\section{3 Structural properties}

X-ray diffraction (XRD) analysis was carried out by removing the annealed film from the substrate with a PAN analytical X-ray spectrometer (PW1830, Philips) with $\mathrm{Cu} \mathrm{K \alpha}$ radiation $\left(\lambda=1.54 \AA, 2 \theta=20^{\circ}-80^{\circ}\right)$ at room temperature. All the peaks are corresponded to $\gamma$ phase of alumina as shown in Fig. 5.

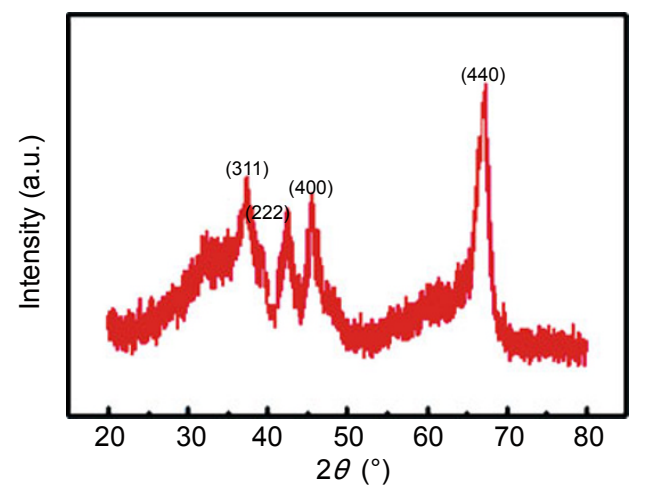

Fig. 5 XRD micrograph of $\gamma$-phase alumina film.

\subsection{Surface morphology of thin film}

Field emission scanning electron microscope (FEI, Nova Nano SEM 450) was used for surface structure analysis as shown in Fig. 6. The micrographs show the effect of binder (PVA) concentration on the morphology of thin films. Figure 6(a) shows thin film
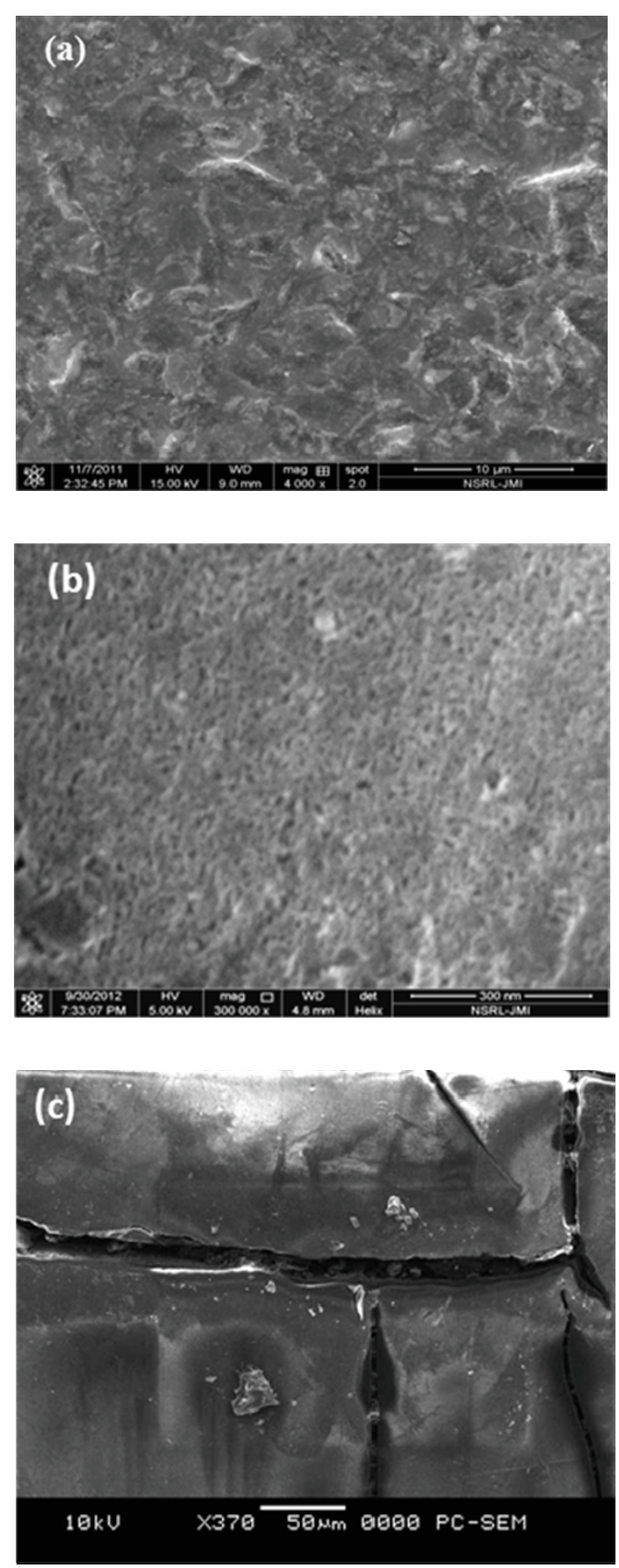

Fig. 6 Scanning electron micrographs of $\gamma$-phase alumina thin film with (a) $0.5 \mathrm{~g}$ PVA, (b) $1.0 \mathrm{~g}$ PVA, (c) $1.5 \mathrm{~g}$ PVA. 
with less porosity, whereas Fig. 6(b) shows a film having high degree of porosity with a large enhancement of the active surface, responsible for the high sensitivity towards moisture and being best suitable for developing moisture sensor. Figure 6(c) shows a film which is full of cracks and is completely discarded for further process.

Roughness of the film (which contained optimum amount of binder that was $1.0 \mathrm{~g}$ in $50 \mathrm{ml}$ sol) surface was checked by atomic force microscopy (AFM, Solver Next, NT-MDT) measurement. The contact mode measurement was followed with the tip radius of $20 \mathrm{~nm}$. Roughness or porosity also depends on homogeneity and rigidity of thin film over the substrate. AFM image (Fig. 7) shows high roughness or porosity which is first priority in sensing application.

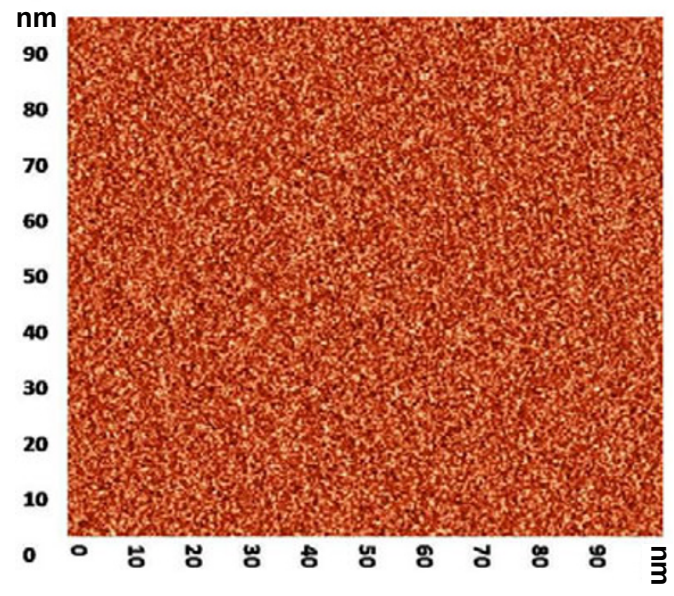

Fig. 7 AFM image of alumina thin film.

\section{5 Sensing performance of sensor}

The electrical characterization of the sensors was determined by placing the sensors in sample holder which was made up of stainless steel. Various concentrations of moisture were achieved by mixing dry nitrogen gas with a desired amount of moist air. The mixing gas flow rate was set to $50 \mathrm{ml} / \mathrm{min}$. Dielectric analysis was performed by semiconductor characterization system (4200 SCS, Keithley) and trace moisture variation was monitored by a SHAW dew point meter (model No. SADPTR-R, UK) which is a commercial moisture sensor as illustrated in Fig. 8.

\subsection{Sensitivity}

The measurement has been performed from $5 \mathrm{ppmV}$ to $500 \mathrm{ppmV}$ at room temperature. At specific ppmV level of moisture, the capacitance has been recorded for $30 \mathrm{~min}$. The sensitivity is defined by the slope or gradient of the capacitance to moisture curve.

The capacitance versus moisture level at $1 \mathrm{kHz}$ (Fig. 9) shows the linear dependence between moisture and capacitance. The sensitivity is $1.11 \mathrm{pF} / \mathrm{ppmV}$ for the range of 5-500 ppmV.

\section{5. 2 Response and recovery time}

Response and recovery characteristics have been observed by applying moist gas of 4-10 ppmV repeatedly. Figure 10 shows the response and recovery curve and it is observed that the response time is $20 \mathrm{~s}$ and recovery time is $30 \mathrm{~s}$. Comparison between fabricated moisture sensor and commercial SHAW moisture sensor is shown in Table 3.

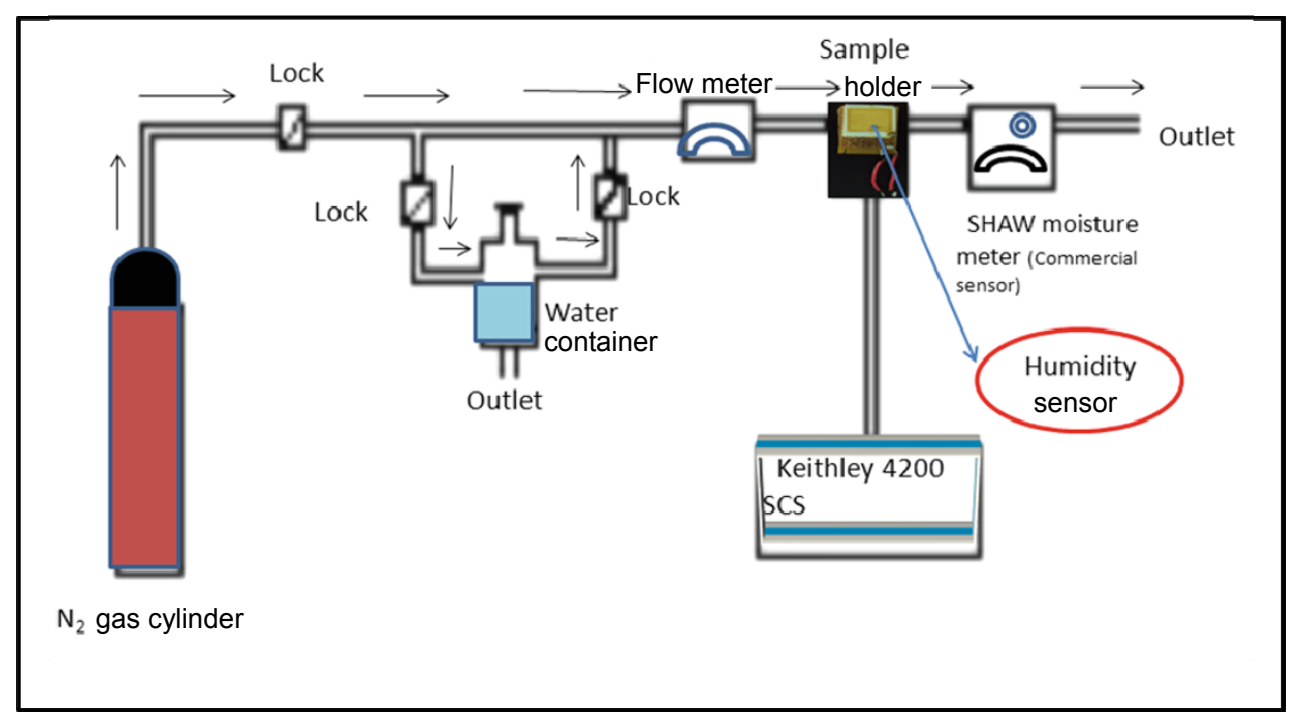

Fig. 8 Moisture sensing setup. 


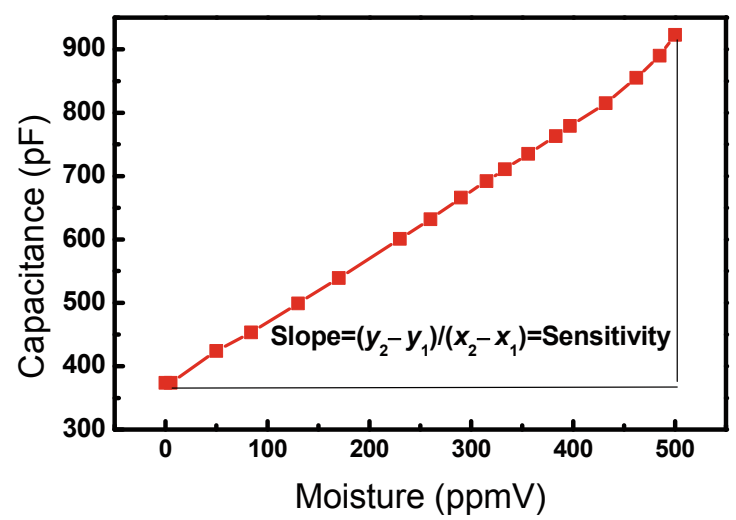

Fig. 9 Capacitance versus humidity curve.

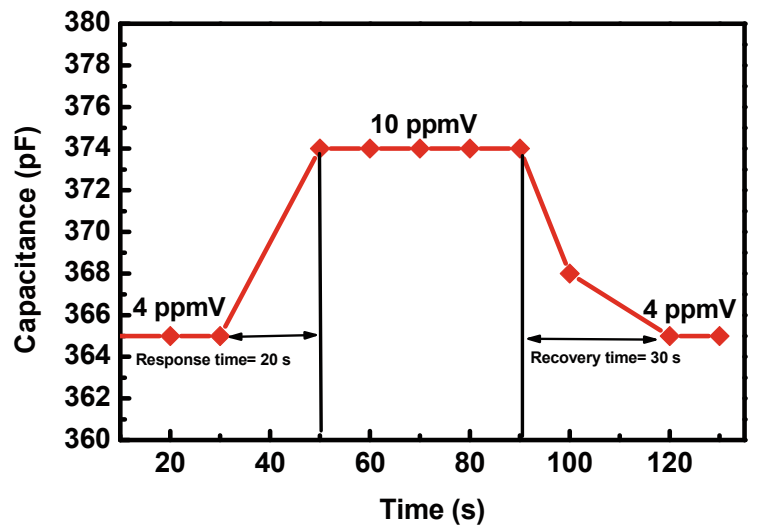

Fig. 10 Response and recovery time of humidity sensor.

Table 3 Comparison of output response of developed sensor with a commercial SHAW moisture analyzer

\begin{tabular}{cccc}
\hline Type of sensor & $\begin{array}{c}\text { Sensitivity } \\
(\mathrm{pF} / \mathrm{ppmV})\end{array}$ & $\begin{array}{c}\text { Range } \\
(\mathrm{ppmV})\end{array}$ & $\begin{array}{c}\text { Response time } \\
(\mathrm{s})\end{array}$ \\
\hline $\begin{array}{c}\text { SHAW moisture } \\
\text { sensor }\end{array}$ & 1.05 & $0-1000$ & 258 \\
$\begin{array}{c}\gamma \text {-phase moisture } \\
\text { sensor }\end{array}$ & 1.11 & $5-500$ & 20 \\
\hline
\end{tabular}

\section{Conclusions}

The thin film of alumina prepared by sol-gel technology was investigated as a capacitive humidity sensor. Rigidity of thin film was achieved by binder optimization and controlling the contact angle over the substrate. It also found the linear variation of trace moisture from $5 \mathrm{ppmV}$ to $500 \mathrm{ppmV}$. Sensitivity and resolution were also good due to the presence of high surface area as a result large change in capacitance with the absorption of moisture. The outcome of our studies accomplished that $\gamma$ phase in alumina would be preferred for fabrication of trace moisture sensor.
Open Access: This article is distributed under the terms of the Creative Commons Attribution License which permits any use, distribution, and reproduction in any medium, provided the original author(s) and the source are credited.

\section{References}

[1] Chen Y-T, Hsu W-T, Najafi K, et al. Vacuum packaging technology using localized aluminum/ silicon-to-glass bonding. J Microelectromech $S 2002$, 11: $556-565$.

[2] Harsányi G. Polymer Films in Sensors Applications. Budapest: Technomic Publishing Company, 1995.

[3] Mistry KK, Saha D, Sengupta K. Sol-gel processed $\mathrm{Al}_{2} \mathrm{O}_{3}$ thick film template as sensitive capacitive trace moisture sensor. Sensor Actuat B: Chem 2005, 106: 258-262.

[4] Bagwell RB, Messing GL. Critical factors in the production of sol-gel derived porous alumina. Key Eng Mat 1996, 115: 45-64.

[5] Ecsedi Z. Synthesis of tailored porosity materials using the sol-gel method. Chem Bull "POLITEHNICA" Univ (Timişoara) 2007, 52: 14-17.

[6] Yoldas BE. Alumina gels that form porous transparent $\mathrm{Al}_{2} \mathrm{O}_{3}$. J Mater Sci 1975, 10: 1856-1860.

[7] Chatterjee S, Basu S, Chattopadhyay D, et al. Humidity sensor using porous tape cast alumina substrate. Rev Sci Instrum 2001, 72: 2792-2795.

[8] Islam T, Mistry KK, Sengupta K, et al. Measurement of gas moisture in ppm range using porous silicon and porous alumina sensor. Sens Mater 2004, 16: 345-356.

[9] Basu S, Saha M, Chatterjee S, et al. Porous ceramic sensor for measurement of gas moisture sensor in the ppm range. Mater Lett 2001, 49: 29-33.

[10] Basu S, Chatterjee S, Saha M, et al. Study of electrical characteristics of porous alumina sensors for detection of low moisture in gases. Sensor Actuat B: Chem 2001, 79: 182-186.

[11] Saha D, Das S, Sengupta K. Development of commercial nanoporous trace moisture sensor following sol-gel thin film technique. Sensor Actuat B: Chem 2008, 128: 383-387.

[12] Adamczyk Z, Weroński P. Application of the DLVO theory for particle deposition problems. Adv Colloid Interfac 1999, 83: 137-226.

[13] Pettersson A, Marino G, Pursiheimo A, et al. Electrosteric stabilization of $\mathrm{Al}_{2} \mathrm{O}_{3}, \mathrm{ZrO}_{2}$, and $3 \mathrm{Y}-\mathrm{ZrO}_{2}$ suspensions: Effect of dissociation and type of polyelectrolyte. J Colloid Interface Sci 2000, 228: 73-81.

[14] Pandey M, Tyagi K, Mishra P, et al. Nanoporous morphology of alumina films prepared by sol-gel dip coating method on alumina substrate. $J$ Sol-Gel Sci Technol 2012, 64: 282-288. 